\title{
Equilibrium of Treg/Th17 cells of peripheral blood in syphilitic patients with sero-resistance
}

\author{
JIANBIN ZHAO, JIE MA, XIAOYAN ZHANG, QING LI and XUEPING YANG \\ Department of Dermatology, The First People's Hospital of Xuzhou, Xuzhou, Jiangsu 221002, P.R. China
}

Received December 7, 2015; Accepted March 22, 2016

DOI: 10.3892/etm.2016.3178

\begin{abstract}
The aim of the present study was to examine changes of cellular homeostasis in regulatory $\mathrm{T}$ (Treg) and T helper 17 (Th17) cells by detecting the proportion of Treg and Th17 cells of peripheral blood, as well as the expression of specific transcription factors in these two types of cells, in syphilitic patients with sero-resistance. A total of 49 subjects were enrolled in the study and divided into two groups, comprising 26 cases of sero-resistant syphilitic patients in the experimental group, and 23 cases of healthy donors in the normal control group. Flow cytometry was applied to examine the proportion of Treg and Th17 cells, as well as the quantitative expression of relevant specific transcription factors [forkhead box P3 (Foxp3) and retinoic acid-related orphan receptor $\gamma \mathrm{t}(\mathrm{ROR}-\gamma \mathrm{t})]$ in the two groups. A correlation analysis was subsequently performed. The results showed that in syphilitic patients with sero-resistance, the proportion of peripheral blood Treg cells was obviously higher than that of the normal control group $(\mathrm{p}<0.01)$ and the proportion of Th17 cells was significantly lower than that of the normal control group $(\mathrm{p}<0.01)$. In addition, the expression of transcription factor Foxp3 in $\mathrm{CD}^{+} \mathrm{T}$ cells was higher than that of the normal control group, while the expression of ROR- $\gamma$ t was lower than that of the normal control $(\mathrm{p}<0.05)$. The expression of Foxp3 and ROR- $\gamma \mathrm{t}$ in peripheral blood CD4 ${ }^{+} \mathrm{T}$ cells had a negative correlation $(\mathrm{r}=-0.481, \mathrm{p}<0.01)$. In conclusion, the peripheral blood of syphilitic patients with sero-resistance may have abnormalities in Treg/Th17 cellular balance.
\end{abstract}

\section{Introduction}

The discovery of penicillin was crucial to the cure of syphilis. However, the increase of syphilitic sero-resistance in recent years has led to the cure of syphilis facing new challenges.

Correspondence to: Dr Jianbin Zhao, Department of Dermatology, The First People's Hospital of Xuzhou, 19 Zhongshan North Road, Xuzhou, Jiangsu 221002, P.R. China

E-mail: ibg746@163.com

Key words: syphilis, sero-resistance, regulatory T cells, T helper 17 cells
Early-stage syphilis patients undergoing regular treatment and whose serum rapid plasma reagin (RPR) test titer is not negatively conversed within 2 years indicate a condition of sero-resistance (with elimination of neurosyphilis) (1). Once sero-resistance occurs, an increase in the dose of penicillin and prolonging the course of treatment cannot usually make serum converse negatively. Due to the $35 \%$ recurrence rate of patients with sero-resistance (1), together with the influence of social factors, this phenomenon has become an important clinical and social issue.

Although various theories concerning the formative cause of sero-resistance have been posited, the exact pathogenesis remains unknown. In previously conducted clinical studies on immunologic changes to patients with primary syphilis, secondary syphilis, latent syphilis, as well as patients with sero-resistance syphilis (2-4), it was identified that in various immunological indicators, $\mathrm{CD} 4{ }^{+} \mathrm{CD} 25^{+}$regulatory $\mathrm{T}$ (Treg) cells showed more specific changes in patients with sero-resistance and whose proportion of $\mathrm{CD} 4^{+} \mathrm{CD} 25^{+}$Treg cells was obviously higher than those in other syphilitic groups (3). It has been suggested that Treg cells may play an important role in the process of sero-resistance formation.

The newly identified Treg cells and T helper 17 (Th17) cells have triggered endless relative research. A balance of the two cell types has especially drawn the attention of scholars in recent years. Previous findings showed that the abnormality of Treg/Th17 cellular balance is associated with numerous diseases (5). Thus, whether there is any abnormality of Treg/Th17 cellular balance in syphilitic patients with sero-resistance and whether the change of Treg cells identified earlier the result of this change in balance, remains to be considered. The aim of the study was to examine the proportion and correlation of Treg and Th17 cells in syphilic patients with sero-resistance.

\section{Materials and methods}

Study participants. A total of 49 subjects were enrolled in the study and divided into two groups. The experimental group consisted of 26 sero-resistant syphilitic patients, 16 males and 10 females, aged between 25 and 59 years (mean age, $31.8 \pm 8.2$ years). The normal control group comprised 23 non-syphilitic healthy donors, 14 males and 9 females, aged between 21 and 40 (mean age, 27.6 \pm 5.7 years). The 26 subjects with syphilis were outpatients of The First People's Hospital of 

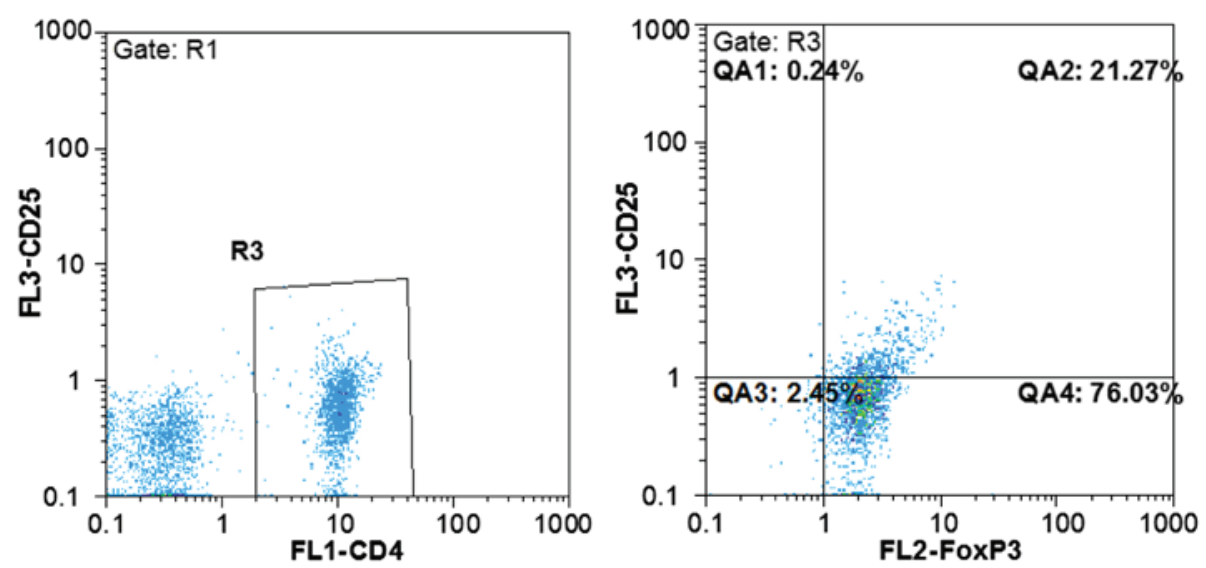

Figure 1. Flow cytometric mapping of the $\mathrm{CD} 4^{+} \mathrm{CD} 25^{+} \mathrm{Foxp} 3^{+}$cells in peripheral blood withdrawn from the syphilitic patients with sero-resistance. Foxp3, forkhead box P3.

Xuzhou. Criteria used for patients with sero-resistance were: Patients diagnosed with syphilis, following regular treatment, whose RPR test did not turn negative after continuous follow up of 2 years (reinfection, neurosyphilis and HIV infection were eliminated). The distribution of RPR titers in patients were as follows: 8 cases of 1:1, 7 cases of 1:2, 6 cases of 1:4, 4 cases of 1:8, 1 case of 1:16. The stage of syphilis following the initial treatment was: 1 case of primary syphilis, 4 cases of secondary syphilis, and 21 cases of latent syphilis.

The experimental protocol of the present study was approved by the Hospital's Ethics Committee. Participants in the two groups provided written informed consent.

Equipment. Flow cytometry (PAS model; Sysmex Partec $\mathrm{GmbH}$, Gorlitz, Germany) was applied to determine the proportion of Treg and Th17 cells.

Antibodies and reagents. Fluorescently-labeled mouse anti-human monoclonal antibody: Anti-CD4-FITC (host/isotype: mouse IgG1, cat. no. 11-0049, clone: RPA-T4, concentration: $5 \mu \mathrm{l} /$ test); anti-CD25-PerCP-Cy5.5 (host/isotype: mouse IgG1, cat. no.: 12-0259, clone: BC96, concentration: $5 \mu \mathrm{l} /$ test); anti- Foxp3-PE (host/isotype: rat IgG2a, catalog no.: 12-4776, clone: PCH101, concentration: $5 \mu \mathrm{l} /$ test); anti-ROR-t-PE (host/isotype: rat IgG2a, cat. no.: 12-6988, clone: AFKJS-9, concentration: $0.2 \mathrm{mg} / \mathrm{ml}$ ); anti-IL-17-PE (host/isotype: mouse IgG1, cat. no.: 12-7178, clone: eBio64CAP17, concentration: $5 \mu \mathrm{l} /$ test) and homotypic control antibody with a corresponding fluorescent label were purchased from eBioscience company (San Diego, CA, USA). A QuantiBRITE PE flow quantification kit was purchased from BD Biosciences (San Jose, CA, USA). Foxp3 fixation/permeabilization concentrate and diluent was purchased from eBioscience Company. Phorbol 12-myristate 13-acetate (PMA), Ionomycin and Brefeldin A (BFA), were purchased from Enzo Life Sciences, Inc. (Farmingdale, NY, USA). RPMI-1640 was purchased from Sigma Company (St. Louis, MO, USA).

Specimen preparation. Density gradient centrifugation was used to isolate peripheral blood mononuclear cells (PBMC) from a $5 \mathrm{ml}$ sample of peripheral blood (with heparin added as

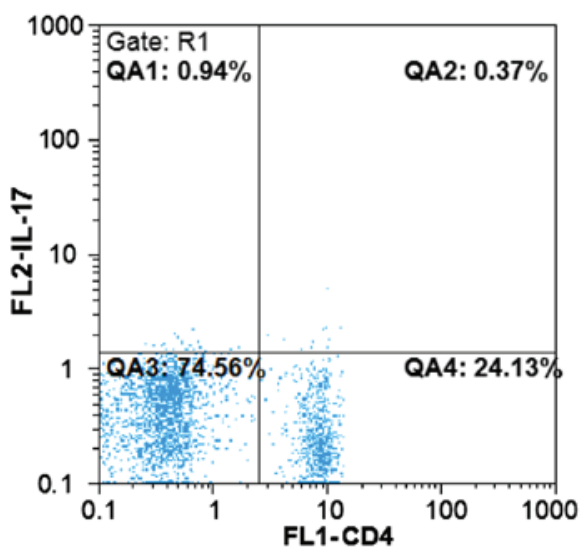

Figure 2. Flow cytometric mapping of the proportion of CD4 $4^{+} \mathrm{IL}-17^{+}$cells in peripheral blood withdrawn from the syphilitic patients with sero-resistance. IL, interleukin.

an anticoagulant), RPMI-1640 was then used at a concentration of $6 \times 10^{6} / \mathrm{ml}$ to perform resuspension as a standby.

Due to the relatively low concentration of the interleukin (IL)-17 molecule in cells, PBMCs were cultured in vitro prior to detection of the targeted molecules. The cell suspension $(500 \mu \mathrm{l})$ with a corresponding amount of PMA, ionomycin and BFA were added at the working concentrations of $25 \mathrm{ng} / \mathrm{ml}$, $1 \mu \mathrm{g} / \mathrm{ml}$, and $10 \mu \mathrm{g} / \mathrm{ml}$, respectively. The cells were then incubated for $4 \mathrm{~h}$ at $37^{\circ} \mathrm{C}, 5 \% \mathrm{CO}_{2}$, as a standby.

Detection of the proportion of Treg cells. Fluorescently-labeled antibodies were used to detect Foxp3 molecules in CD4 and CD25 antigens located at the surface of Treg cells. To this end, uncultured PBMC suspension was added into four test tubes, and in three of these, a corresponding homotypic control antibody was added as a negative control. Anti-CD4-FITC and anti-CD25-PerCP-Cy5.5 antibodies were added into the test tubes and incubated for $20 \mathrm{~min}$, at $4^{\circ} \mathrm{C}$, in the dark. The fix/perm reagent was added according to product protocol instruction, followed by $30 \mathrm{~min}$ of incubation at $4^{\circ} \mathrm{C}$. Following permeabilization, anti-Foxp3-PE antibody was added, and the cell suspension was incubated for $20 \mathrm{~min}$ at $4^{\circ} \mathrm{C}$, in the dark. After washing the sample, the phosphate-buffered saline suspension was subjected to flow cytometric analysis to 


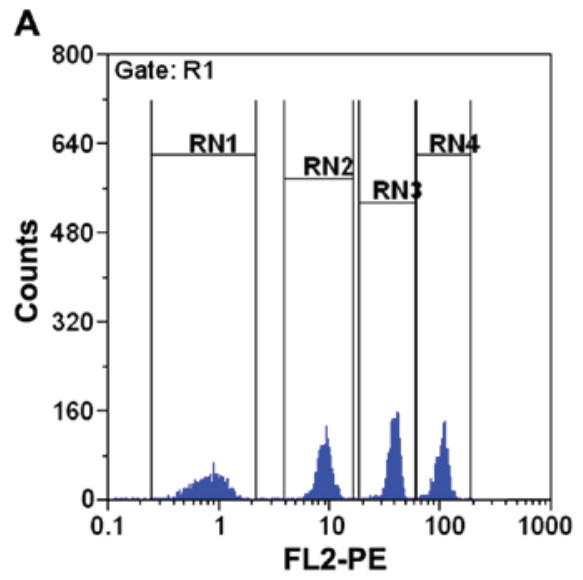

$\mathbf{B}$

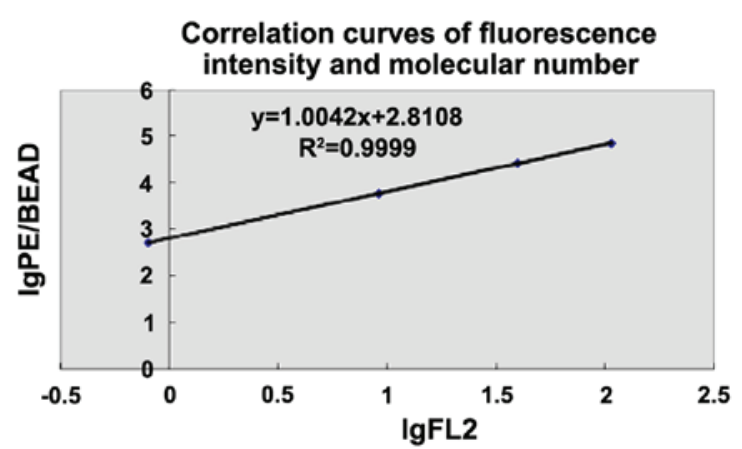

Figure 3. Flow cytometric mapping of fluorescent quantitative microballoon coated with (A) phycoerythrin (PE) molecules at varied concentrations. In this experiment, the mean fluorescence intensity and the number of (B) coated PE molecules of different microballoon groups were taken to logarithm to obtain the regression equation.
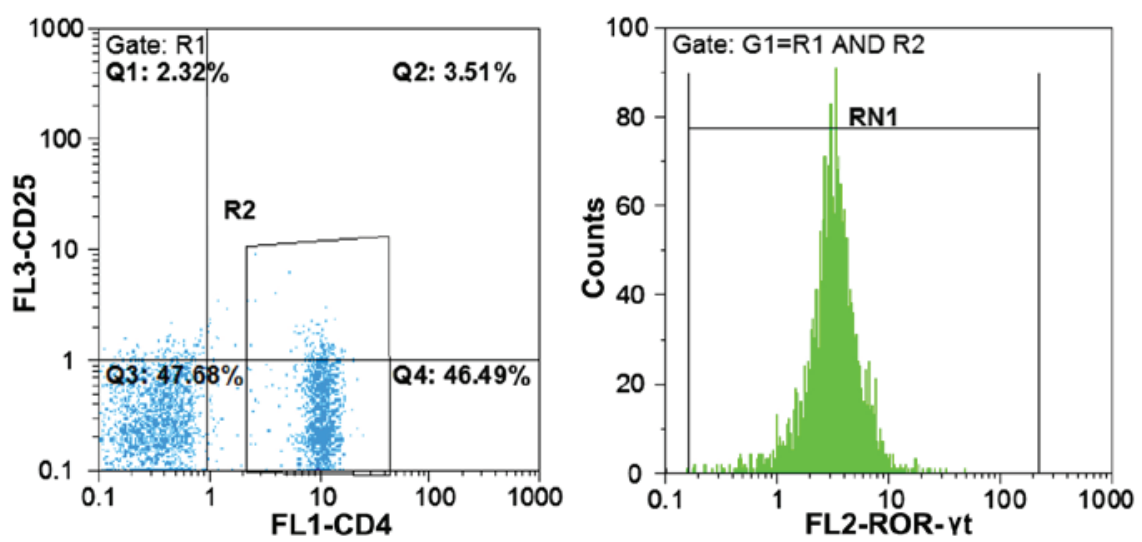

Figure 4. Flow cytometric mapping of the expression of forkhead box P3 and retinoic acid-related orphan receptor $\gamma \mathrm{t}\left(\mathrm{ROR}-\gamma_{\mathrm{t}}\right)$ molecules in $\mathrm{CD} 4^{+}$cells of peripheral blood.

determine the proportion of $\mathrm{CD} 4^{+} \mathrm{CD} 25^{+} \mathrm{Foxp} 3^{+}$cells in $\mathrm{CD} 4^{+}$ cells (Fig. 1).

Detection for the proportion of Th17 cells. Cultured PBMC suspension was processed in accordance with the flow cytometric testing mentioned earlier, with the cell surface labeled by anti-CD4-FITC antibody. PE-labeled monoclonal IL-17 antibody was added to detect intracellular molecules. The cell suspension was washed and subjected to flow cytometric analysis to determine the proportion of $\mathrm{CD} 4^{+} \mathrm{IL}-17^{+}$cells in CD4 ${ }^{+}$cells (Fig. 2).

Quantitative flow cytometry for Foxp3 and ROR- $\gamma$ t cell molecules. The QuantiBRITE PE flow quantitative kit was used under the same flow cytometric conditions as were applied to the samples. The operational procedures were in accordance with the protocol specifications. Quantitative microballoon coated with PE molecules of different concentrations was mixed and detected using flow cytometry. The geometric mean of the fluorescent intensities (GFMI) of the microballoon in each group was obtained. The GFMI and the number of coated PE molecules of different microballoon groups were taken to logarithm to obtain the regression equation (Fig. 3).
Uncultured PBMC cell suspension, performed using flow cytometry, was initially labeled using CD4-FITC antibody on cell surface. PE-labeled monoclonal antibodies were subsequently used to detect the intracellular molecules of Foxp3 and ROR- $\gamma$ t. (Fig. 4).

The measured GMFI values of related molecules in single cells underwent the regression equation to identify the corresponding expression quantity of targeted molecules.

A correlation analysis was conducted on the expression data of FoxP3 and ROR- $\gamma$ t molecules in $\mathrm{CD}^{+} \mathrm{T}$ cells.

Statistical analysis. SPSS 11.0 statistical software (SPSS, Inc., Chicago, IL, USA) was used in our data analysis. Since the numerical data did not meet normal distribution, non-parametric tests including the Mann-Whitney $U$ test for data analysis and the Spearman rank test for correlation analysis were employed. $\mathrm{P}<0.05$ was considered to indicate a statistically significant difference.

\section{Results}

Dection of the proportion of Treg and Th17 cells. Results of the present study detected the proportion of Treg and Th17 cells in 
Table I. Proportion of peripheral blood Treg and Th17 cells, and expression of the corresponding transcription factors in patients with sero-resistance and normal controls (mean \pm standard deviation).

\begin{tabular}{lccccc}
\hline Groups & Cases & $\mathrm{CD}^{+} \mathrm{CD} 25^{+} \mathrm{Foxp}^{+} \mathrm{T}$ cells $(\%)$ & $\mathrm{CD}^{+} \mathrm{IL}^{+17^{+}}$T cells $(\%)$ & Foxp3 expression & ROR- $\gamma_{\text {t expression }}$ \\
\hline Sero-resistance & 26 & $33.28 \pm 11.84$ & $3.17 \pm 2.32$ & $2994.86 \pm 1099.18$ & $1473.12 \pm 752.20$ \\
Normal control & 23 & $22.13 \pm 7.79$ & $8.87 \pm 2.00$ & $2539.72 \pm 1086.96$ & $1778.34 \pm 388.13$ \\
U-value & 123 & 32 & 198 & 200 \\
P-value & $<0.01$ & $<0.01$ & $<0.05$ & $<0.05$ \\
\hline
\end{tabular}

Treg, regulatory T; Th17, T helper 17; Foxp3, forkhead box P3; ROR- $\gamma$ t, retinoic acid-related orphan receptor $\gamma \mathrm{t}$.

peripheral blood of enrolled participants, and determined the quantitative expression of relevant specific transcription factors (Foxp3 and ROR- $\gamma$ t) using flow cytometry (Figs. 1-4). The results showed that the proportion of Treg cells in peripheral blood withdrawn from syphilitic patients with sero-resistance was significantly higher than that of the normal control group $(p<0.01)$, and that the proportion of Th17 cells was significantly lower than that of the normal control group $(\mathrm{p}<0.01)$. Additionally, the expression of transcription factor Foxp3 in $\mathrm{CD}^{+} \mathrm{T}$ cells from syphilitic patients with sero-resistance was higher than that in the normal control group, while the expression of ROR- $\gamma$ t was lower in comparison to the normal control $(\mathrm{p}<0.05)$.

Scattering correlation of the expression between Foxp3 and $R O R-\gamma t$. Correlation of the expression of Foxp3 and ROR- $\gamma$ t in peripheral blood $\mathrm{CD}^{+} \mathrm{T}$ cells had a negative correlation when the samples were taken together $(r=-0.481, \mathrm{P}<0.01$, Fig. 5).

\section{Discussion}

Treg and Th17 cells are dependent Th cell subsets that are different from Th1 and Th2 cells. Treg cells have immunosuppressive characteristics and may express the specific transcription factor Foxp3 (5). Th17 may evoke an inflammatory response through the secretion of IL-17, whose specific transcription factor is ROR- $\gamma$ t. Previous findings have shown that the two play an important role in the occurrence and development of infectious diseases, autoimmune diseases and tumors (5). Notably, these two functionally antagonistic cells are derived from the same naïve $\mathrm{CD} 4^{+} \mathrm{T}$ cells under the influence of the same transforming growth factor (TGF)- $\beta$ cell factor (5). TGF- $\beta$, when exiting alone, can evoke naïve $\mathrm{CD}^{+} \mathrm{T}$ cells to express Foxp3. Since Foxp3 restrains the function of ROR- $\gamma \mathrm{t}$, it promotes the differentiation of Treg cell and restrains the generation of Th17 cells (6). However, Bettelli et al (7) demonstrated that it has been the combined action of TGF- $\beta$ and IL- 6 may be counter-productive, promoting the differentiation of Th17 cells (7).

Based on these findings, it has been hypothesized (5) that there is a balance between Treg/Th17 cells in the human body, and that the occurrence of certain diseases may be caused by the imbalance of Treg/Th17 cells in the process of naïve CD4 ${ }^{+}$ $\mathrm{T}$ cell differentiation. This hypothesis replenished the former Th1/Th2 balanced model, and provided a new theoretical basis for some phenomena that could not be explained by the

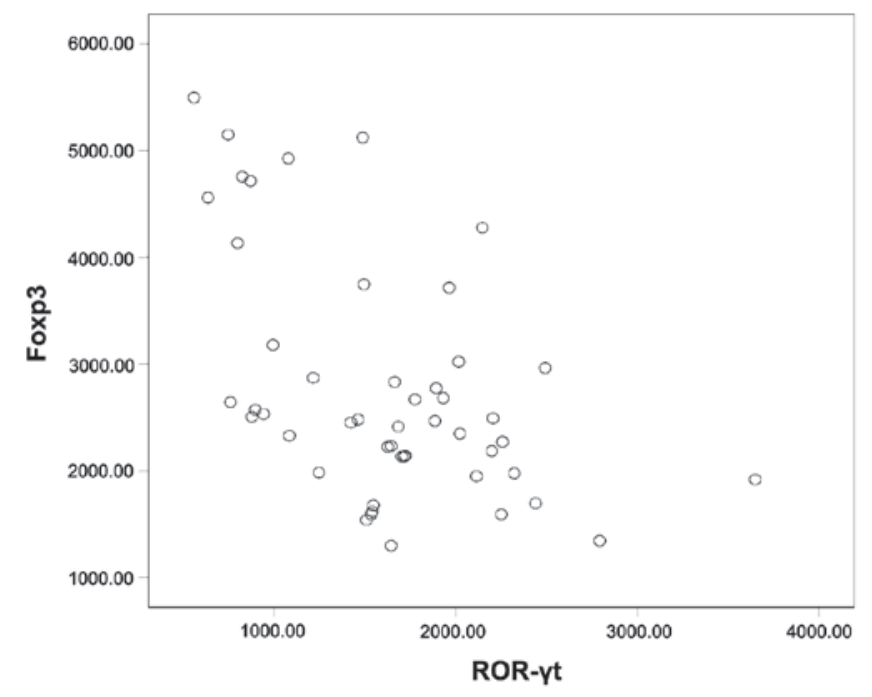

Figure 5. Scattering correlation of expressions between forkhead box P3 (Foxp3) and retinoic acid-related orphan receptor $\gamma \mathrm{t}(\mathrm{ROR}-\gamma \mathrm{t})$ in $\mathrm{CD} 4^{+}$ $\mathrm{T}$ cells of peripheral blood of all the samples.

Th1/Th2 model. It was assumed that, by adjusting the balance between Treg and Th17, new treatment strategies could be developed to resume the immune homeostasis. In recent years, some investigators have attempted to examine this method in vitro, using animal models and even in human subjects with autoimmune diseases, as well as various proinflammatory cytokine antagonists such as IL-6 and IL-1 antagonists $(8,9)$, IL-2 (10), retinoic acid (11), interferon (12), and environmental toxins (13), with a certain degree of efficacy, some of which showed promising results.

The results of the current study showed that the proportion of Treg cells and the expression of Foxp3 in peripheral blood lymphocytes from syphilitic patients with sero-resistance were higher than those from the normal control group, while the proportion of Th17 cells and the expression of ROR- $\gamma$ t were all lower than those of the normal control group. The differences were statistically significant. At the same time, when samples from all the subjects were taken into consideration, the expression of Foxp3 was negatively correlated with the expression of ROR- $\gamma \mathrm{t}$ in $\mathrm{CD}^{+}{ }^{+} \mathrm{T}$ lymphocytes. Based on the present experimental results and the aforementioned Treg/Th17 balance theory, we suggest that Treg and Th17 cells were antagonistic with each other in order to maintain a dynamic equilibrium. Such an equilibrium in syphilitic patients with sero-resistance 
may offset Treg cells, promoting the differentiation of initial $\mathrm{CD}^{+} \mathrm{T}$ cells to Treg cells and restraining the occurrence of Th17 cells, thus leading to cell immunosuppression. In clinical treatment, although a full dose of antibiotics was used, internal treponema pallidums were, due to the cellular immunosuppression of the patients, not cleaned thoroughly, which may stimulate the body to generate antibodies resulting in the development of sero-resistance. This may partly explain the reason for the high recurrence in patients, though the underlying cause for this phenomenon remains to be elucidated. However, whether these patients are congenitally susceptible, or whether it is the long dormant treponema pallidums that lead to the abnormality of the immune system remains to be determined. While some studies indicated a higher proportion of latent syphilis leading to sero-resistance (14), additional studies are required to address these issues.

The antibiotic treatment of syphilis is beneficial only with a normally working immune system of the body (15). The results showed the presence of abnormality of the immunological state in syphilitic patients with sero-resistance. This finding suggests that in addition to the primary antibiotics treatment, we should also pay close attention to patients' immunological state in the future clinical management of syphilis, which may lead to the formulation of individualized immunological intervention treatments.

In conclusion, the peripheral blood of syphilitic patients with sero-resistance may have abnormalities in the Treg/Th17 cellular balance, and these abnormalities may be associated with the development of this phenomenon. Potential treatments aiming to adjust the balance between Treg/Th17 may be useful for sero-resistance in syphilitic patients.

\section{Acknowledgements}

This study was supported by the National Natural Science Foundation of China (project no. 30700718) and Social Development Project of Science and Technology of Xuzhou City (project no. XF10C057).

\section{References}

1. Dejung S, Rampini SS and Battegay E: [Syphilis: Diagnosis andtreatment monitoring]. Praxis (Bern 1994) 100: 1445-1448, quiz 1449-1450, 2011.
2. Leader BT, Godornes C, VanVoorhis WC and Lukehart SA: $\mathrm{CD} 4^{+}$lymphocytes and gamma interferon predominate in local immune responses in early experimental syphilis. Infect Immun 75: 3021-3026, 2007.

3. Li K, Wang C, Lu H, Gu X, Guan Z and Zhou P: Regulatory $\mathrm{T}$ cells in peripheral blood and cerebrospinal fluid of syphilis patients with and without neurological involvement. PLoS Negl Trop Dis 7: e2528, 2013.

4. Zhu A, Han H, Zhao H, Hu J, Jiang C, Xie F and Wang F: Increased frequencies of Th17 and Th22 cells in the peripheral blood of patients with secondary syphilis. FEMS Immunol Med Microbiol 66: 299-306, 2012.

5. Eisenstein EM and Williams CB: The T(reg)/Th17 cell balance: A new paradigm for autoimmunity. Pediatr Res 65: 26R-31R, 2009.

6. Zhou L, Lopes JE, Chong MM, Ivanov II, Min R, Victora GD, Shen Y, Du J, Rubtsov YP, Rudensky AY, et al: TGF-beta-induced Foxp3 inhibits $\mathrm{T}(\mathrm{H}) 17$ cell differentiation by antagonizing RORgammat function. Nature 453: 236-240, 2008

7. Bettelli E, Carrier Y, Gao W, Korn T, Strom TB, Oukka M, Weiner HL and Kuchroo VK: Reciprocal developmental pathways for the generation of pathogenic effector TH17 and regulatory T cells. Nature 441: 235-238, 2006.

8. Serada S, Fujimoto M, Mihara M, Koike N, Ohsugi Y, Nomura S, Yoshida H, Nishikawa T, Terabe F, Ohkawara T, et al: IL-6 blockade inhibits the induction of myelin antigen-specific Th17 cells and Th1 cells in experimental autoimmune encephalomyelitis. Proc Natl Acad Sci USA 105: 9041-9046, 2008.

9. Cho ML, Kang JW, Moon YM, Nam HJ, Jhun JY, Heo SB, Jin HT, Min SY, Ju JH, Park KS, et al: STAT3 and NF-kappaB signal pathway is required for IL-23-mediated IL-17 production in spontaneous arthritis animal model IL-1 receptor antagonist-deficient mice. J Immunol 176: 5652-5661, 2006.

10. Laurence A, Tato CM, Davidson TS, Kanno Y, Chen Z, Yao Z, Blank RB, Meylan F, Siegel R, Hennighausen L, et al: Interleukin-2 signaling via STAT5 constrains T helper 17 cell generation. Immunity 26: 371-381, 2007.

11. Elias KM, Laurence A, Davidson TS, Stephens G, Kanno Y, Shevach EM and O'Shea JJ: Retinoic acid inhibits Th17 polarization and enhances FoxP3 expression through a Stat-3/Stat-5 independent signaling pathway. Blood 111: 1013-1020, 2008.

12. Shinohara ML, Kim JH, Garcia VA and Cantor H: Engagement of the type I interferon receptor on dendritic cells inhibits T helper 17 cell development: Role of intracellular osteopontin. Immunity 29: 68-78, 2008.

13. Quintana FJ, Basso AS, Iglesias AH, Korn T, Farez MF, Bettelli E, Caccamo M, Oukka M and Weiner HL: Control of $\mathrm{T}(\mathrm{reg})$ and $\mathrm{T}(\mathrm{H}) 17$ cell differentiation by the aryl hydrocarbon receptor. Nature 453: 65-71, 2008.

14. Li J, Wang LN, Zuo YG, Liu YX, Liu XR, Lei Y and Zheng HY: [Clinical analysis and study of immunological function in syphilis patients with seroresistance]. Zhonghua Yi Xue Za Zhi 89: 813-816, 2009.

15. Podwinska J, Lusiak M, Zaba R and Bowszyc J: The pattern and level of cytokines secreted by Th1 and Th2 lymphocytes of syphilitic patients correlate to the progression of the disease. FEMS Immunol Med Microbiol 28: 1-14, 2000. 